\title{
Considerations for Design and Production of Digital Books for Early Literacy in Ethiopia
}

\author{
TERESA M. DOBSON \\ University of British Columbia \\ MARLENE ASSELIN \\ University of British Columbia
}

\begin{abstract}
ALEMU ABEBE
CODE Ethiopia
\end{abstract}

\begin{abstract}
This paper considers the implications of digital text production models for the development of reading materials for emergent and early readers in the Ethiopian context. We draw from several theoretical frameworks and also from comments of Ethiopian academics, writers, and publishers to ground descriptions of Ethiopian contexts of language and literacy. We then present three different models for the production and curation of digital stories for children and contemplate how these models align with existing literacy traditions and practices. We also raise questions about the potential effects on the development of literary culture and children's literature in Ethiopia of projects aimed at rapidly producing large corpora of literature for children. Ultimately, we pose complicated cultural and linguistic questions that need to be taken into consideration to provide appropriate and original early literacy materials in Ethiopia.
\end{abstract}

Keywords

Ethiopia, early literacy, children's literature, digital texts

\section{Introduction}

Low literacy rates in some majority world contexts are deemed problematic, particularly by the Euro-Western world, and have precipitated intervention in the form of literacy programs (Wickens \& Sandlin, 2007). Such programs promote the use of digital texts as an essential component of urgently needed early literacy programs, primarily as a means to reduce publication costs and increase knowledge mobility (United States Agency for International Development [USAID], 2017). These recommendations are set against a backdrop of a history of donated, context-insensitive books from the Global North that have had little impact on access. Much of the digital material trickling down into the hands of children in the Global South are cultural and linguistic downloads from the same foreign publishers of donated print books, which raises ethical concerns about the appropriateness of texts for children and the development of a local culture of children's literature. And yet a small portion of new texts generated through emergent digital projects do originate internally with local writers, illustrators, and publishers-thereby promising more relevance. 
This paper considers the cultural, linguistic, and technological implications of digital models of text production and curation with a particular focus on the Ethiopian context of language and literacy. To establish this context, we describe Ethiopia's linguistic and cultural diversity, as well as Ethiopian traditions and practices around early reading, book culture, and storytelling. We then present analyses of digital book production projects producing storybooks for children in Ethiopian languages. Multiple theoretical framings inform our discussion of the deeply complex historical, political, religious, social, and economic context of Ethiopian language and literacy. It is this context that digital book production projects need to take into account if the aim is to provide a means of access to original, culturally and linguistically relevant literacy materials for emergent and early readers in Ethiopia.

We also include information and perspectives from Ethiopian academics, writers, and publishers, who emailed answers to a series of questions about their experiences with stories and their views of contemporary children's reading materials in Ethiopia. Perspectives offered through the activities described above illustrate and extend descriptions of the Ethiopian context of language and literacy derived from literature. Subsequently, we planned a focus group discussion with our seven participants about the implications and possibilities of digital book production at the College of Educational and Behavioral Studies at Addis Ababa University. At the request of the Dean of the College, however, we changed the focus group structure to that of a presentation on a local digital book production project. This presentation was open to all faculty and graduate students. Comments and questions from attendees inform the second half of this paper.

The Ethiopian Context: Literacy and Linguistic Diversity in Ethiopia

According to the United Nations Educational, Scientific, and Cultural Organisation (UNESCO) Institute of Statistics (UIS, 2016), the rate of literacy in Ethiopia has dramatically increased over the past 25 years and continues to rise steadily. Figures published for 2015 suggest that almost $70 \%$ of youth are now literate (in comparison to a reported rate for youth of less than 34\% in 1994 and about 55\% in 2007; see Table 1). Over the past few decades there has also been a marked increase reported in literacy rates among girls and women, to the point that the literacy gap between men and women between the ages of 15 and 24 is now reported to be less than 3\% (see Table 2). Joshi and Verspoor (2012) observe that one impetus for change has been the goal set by the Ethiopian government of becoming a "middle-income country" by 2020 to 2023 (MoFED, 2010). Such a goal, Joshi and Verspoor note, is only possible in countries with high rates of literacy among both men and women and a sufficient number of secondary graduates to support a middle-income economy. 
Table 1

Ethiopian Literacy Rates by age for the years 1994, 2007 and 2015 as reported by the UNESCO Institute of Statistics (UIS, 2016).

\begin{tabular}{|l|l|l|l|}
\hline $\begin{array}{l}\text { Literacy Rates } \\
\text { By Year }\end{array}$ & $\begin{array}{l}15-24 \quad \text { years } \\
(\%)\end{array}$ & $\begin{array}{l}15 \text { and older } \\
(\%)\end{array}$ & 65 and older \\
\hline 1994 & 33.59 & 27.01 & no data \\
\hline 2007 & 54.98 & 39 & 13.63 \\
\hline 2015 & 69.49 & 49.03 & 14.47 \\
\hline
\end{tabular}

Table 2

2015 Ethiopian literacy rates by age and gender, as reported by the UNESCO Institute of Statistics (UIS, 2016).

\begin{tabular}{|c|c|c|c|}
\hline $\begin{array}{ll}\text { Literacy } & \text { Rates } \\
2015 & \end{array}$ & Total (\%) & Male (\%) & Female (\%) \\
\hline 15-24 years & 69.49 & 71.13 & 67.82 \\
\hline $\begin{array}{l}15 \text { years and } \\
\text { older }\end{array}$ & 49.03 & 57.28 & 40.97 \\
\hline $\begin{array}{l}65 \text { years and } \\
\text { older }\end{array}$ & 14.47 & 22.51 & 7.52 \\
\hline
\end{tabular}

As acknowledged by the UIS itself, potential shortcomings of any set of national statistics such as those cited above relate to how literacy is defined and the methods by which literacy data is collected. In International Literacy Statistics: A Review of Concepts, Methodology and Current Data (UIS, 2008), author Roy Carr-Hill draws on the work of New Literacy Studies scholars in observing that literacy

only has meaning within its particular context of social practice and does not transfer easily across contexts; there are different literacy practices in different domains of social life, such as education, religion, workplace, public services, and family and community activities. They change over time and these different literacies are supported and shaped by different institutions and social relationships. (UIS, 2008, p. 25)

The question of how literacy rates have been defined and measured over the past 25 years in Ethiopia is beyond the scope of this paper; suffice it to say that the above statistics are offered with the caveat that they are not infallible. Collecting reliable literacy data in Ethiopia is challenging for a number of reasons, not the least of which is that the nation is one of great linguistic and cultural diversity. In responding to the 2007 census, for example, citizens reported over 90 languages as mother tongues and identified themselves as belonging to over 85 distinct ethnic groups (Central Statistical Agency of Ethiopia, 2010). 
In a working paper on the medium of instruction (MoI) in Ethiopian schools, Vujich (2013) offers an overview of key language policies over the past 75 years that have influenced literacy practices and achievement in school. Drawing on Getachew and Derib (2006), he notes that the "first official Ethiopian educational language policy emerged in 1944 in the form of a directive that Amharic was to be the general language of instruction," and that in 1955 Amharic was also "made the official language in Ethiopia's revised constitution, thus extending its use beyond the education sector to the political, legal, and administrative spheres” (Vujich, 2013, p. 3). Notably, however, Amharic has never been the language of the majority in Ethiopia. Census data collected in 2007 shows that only 29\% of the population reported Amharic (or "Amaringa") as a "mother tongue." Afaan Oromo was in fact the most common reported mother tongue (34\%), while the remainder of the population (37\%) reported over 90 other languages as mother tongues (Central Statistical Agency of Ethiopia, 2010). Ultimately, the shift toward an Amharic-speaking state, which has been interpreted by historians as a nation-building and powerconsolidation effort on the part of then Emperor Haile Selassie (Getachew \& Derib, 2006; Smith, 2008; Vujich, 2013), has led to a complex scenario whereby many Ethiopian children-particularly those in regions where Amharic is not dominant (e.g., Oromia, the Southern Nations, Nationalities, and Peoples’ Region [SNNP], Somali, and Tigraydid)— have not had access to education in their first language. Further, at the same time Amharic was set as the medium of instruction (MoI) in early schooling, English was promoted as the MoI in upper primary and secondary schools, as well as in teacher training institutions (Heugh, Benson, Bogale, \& Yohannes, 2007; Vijich, 2013). This meant children had to learn yet another language to gain access to upper elementary and secondary schooling.

Vijich notes that while the "socialist-inspired revolution of 1974 resulted in a formal reversal of Selassie's homogenising policies," in practice, Amharic "remained the language of instruction in primary schools, principally because teachers most often spoke Amharic and were not trained in the use of local mother tongues" (Vijich, 2013, p. 3). The status quo-primary education in Amharic - was nevertheless gradually contested. Data collected by the ministry of education in the mid-1980s showed that performance in science and technology of students with Amharic as a mother tongue was markedly higher than that of students with other first languages, and the disadvantage of the MoI for nonAmharic speakers was identified as a likely cause (Vijich, 2013).

This perspective is in line with developing understandings of the importance of the mother tongue in education (see, for example, an extensive review of research on this topic in the recent Landscape Report on Early Grade Literacy [Kim, Boyle, Zuilkowski, \& Nakamura, 2016]). As Cummins (2001) observes,

When the mother tongue is promoted in school . . . the concepts, language, and literacy skills that children are learning in the majority language can transfer to the home language. In short, both languages nurture each other . . . Bilingual children perform better in school when the school effectively teaches the mother tongue and, where appropriate, develops literacy in that language. By contrast, when children's mother tongue is encouraged to atrophy and its development stagnates, children's personal and conceptual foundation for learning is undermined. (Cummins, 2001, p. 18) 
Cummins further notes that the challenge for educators and policymakers in highly multilingual settings "is to shape the evolution of national identity in such a way that the rights of all citizens (including school children) are respected, and the cultural, linguistic, and economic resources of the nation are maximized" (p. 18). To do other than offer education in the mother tongue, particularly to children attending school in the very communities their ancestors have inhabited for generations, violates the UN Convention on the Rights of the Child (UNCRC), which states that education of children shall be directed toward the "development of respect for the child's parents, his or her own cultural identity, [and] language and values," and that a child "shall not be denied the right, in community with other members of his or her group, to enjoy his or her own culture, to profess and practise his or her own religion, or to use his or her own language” (United Nations, 1989, Articles 29.1.c and 30). The African Charter of Rights and Welfare of the Child, adopted in 1990 by the Organisation of African Unity, builds on the principles of the UNCRCalso emphasizing that children's education should include "the preservation and strengthening of positive African morals, traditional values, and cultures” (OAU, 1990, Article 11).

In keeping with these perspectives, in 1994 a new policy emerged in Ethiopia guaranteeing children the right to primary education in their first language: "Cognizant of the pedagogical advantage of the child in learning in mother tongue and the rights of nationalities to promote the use of their languages, primary education will be given in nationality languages" (Government of Ethiopia, 1994). Even now, however, the implementation of this policy remains challenging in areas of high linguistic diversity for a number of reasons, including (1) the difficulty in finding teachers fluent in local languages; (2) the challenge of offering teacher training in those languages; (3) the paucity of reading materials suitable to the context; and (4) the expense of translation when local reading materials are not available. In the next section of this paper we focus on the third of these challenges - the paucity of reading materials-considering in particular the availability of storybooks that might support early literacy development.

\section{Early Reading, Book Culture, and Storytelling in Ethiopia}

Many researchers have argued that early literacy acquisition is best supported by the extensive reading of storybooks, particularly those that are closely connected to children's home and community environments. Bronfenbrenner's ecological systems theory (1979; Bronfenbrenner \& Morris, 2007), for example, explains the interplay of various embedded contexts (e.g., social, legal, economic, and religious) on human development. For young children's development, the most immediate and influential environment is the microsystem, consisting of the child's family and close community. Applying this perspective to the selection of early reading materials for children, it is widely acknowledged that the stories children hear and learn to read should include those in which they can see themselves and their worlds-the microsystem. Such stories are those that describe characters with whom children can easily relate engaging in recognizable activities, such as familiar childhood games or customary family and community practices. As development progresses, early childhood educators scaffold children's reading materials to extend beyond immediate family and community contexts.

Acknowledging and drawing on children's funds of knowledge (Moll \& Greenberg, 1990) in early learning settings respectfully and effectively supports literacy development, 
especially with children of diversity (Moll \& Gonzalez, 1994). Moll and his colleagues define funds of knowledge as "those historically accumulated and culturally developed bodies of knowledge and skills essential for household or individual functioning and wellbeing” (Moll \& Gonzalez, 1994, p. 443). Similarly, the schema theory of reading proposed by Anderson and Pearson (1984) posits that comprehension requires the ability to relate reading or viewing to one's own schema or knowledge, which includes content knowledge and knowledge of textual forms. Recognizing the funds of knowledge and schemata students bring to classroom settings and providing reading materials that are both linguistically meaningful and culturally relevant allows beginning readers not only to identify with characters, settings, and events, but also to understand vocabulary and cultural themes. Thus, along with the rise of multicultural children's picture books have been discussions of cultural authenticity - in relation to both written content and illustrations (Fox \& Short, 2003). Although some argue for specific definitions, Smith and Wiese (2006) broadly define cultural authenticity as "the extent to which the reteller, adaptor, or illustrator (1) remains reasonably true to the original printed source, (2) accurately and respectfully represents the values and beliefs of the cultural group, and (3) responsibly depicts geographical, historical, and cultural details” (p. 72).

In the Ethiopian context, there is not a long tradition of the publication of the sorts of early reading materials described above - that is, illustrated books for children. This is not because there is no history of literacy and book production in Ethiopia. On the contrary, as Winslow (2015) observes, the Ethiopian tradition of manuscript production is one of the longest in the world, and scribal practices that are centuries old are still practiced where they have been lost elsewhere: "Isolationist for a period of almost 700 years due to geopolitical and religious factors, [Ethiopia] has preserved many practices intact from the medieval period, including the production of parchment manuscripts” (p. 1). Consequently, Winslow remarks, contemporary scholars of manuscript culture look to Ethiopia for an understanding of medieval book production techniques.
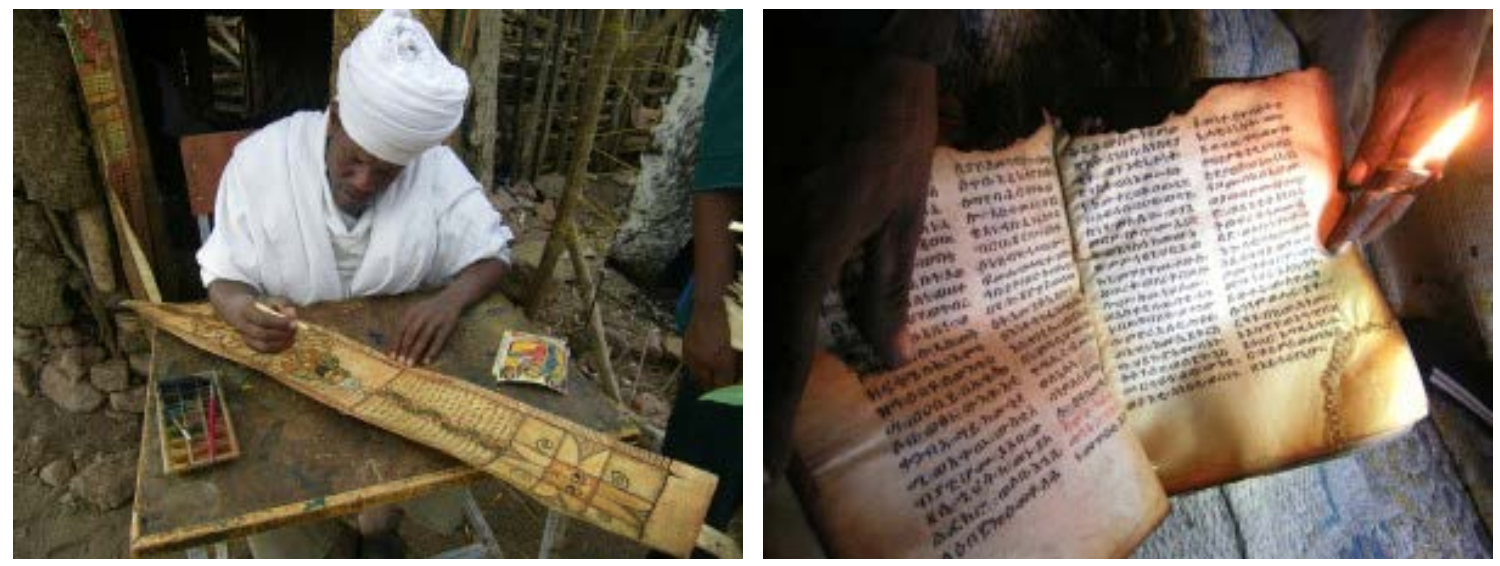

Figure 1. Evidence of a long history of literacy and book culture in Ethiopia: (1) A scribe in Lalibela preparing texts for sale to tourists; (2) a parchment manuscript (date unknown), written in Ge'ez, located in a high-mountain, rock-hewn church approximately $16 \mathrm{~km}$ from Lalibela. Photos: T.M. Dobson personal archives, 2010.

Historically, the primary script used for manuscript production in Ethiopia was Ge'ez, a language for writing liturgical, scholarly, and literary work that is no longer in 
general use beyond the church (Scelta \& Quezzaire-Belle, 2001). Elsewhere, in most settings outside the church, communications were in oral form. Notes McCann (2001), "the written form as a bureaucratic exercise did not supplant the oral tradition until well into the modern era” (p. 85). Not surprisingly, therefore, book culture in Ethiopia is still strongly tied to its liturgical and scholarly origins, and books are serious objects for serious content (Figure 1). Publishing storybooks for children is a unique notion for many in Ethiopia.

Storytelling for children instead remains a primarily oral genre. In an effort to get a sense of perspectives on and experiences with early literacy texts in Ethiopia, we sought input from seven Ethiopian citizens involved in education and book production. These participants, all professionals, included a member of an NGO working in early literacy projects, university faculty in education, an author of children's books in major indigenous Ethiopian languages, and a local publisher. Planned Skype interviews were not possible due to challenges with connectivity, so participants answered questions via email. Asked about the most common types of stories in their own homes growing up, they listed riddles, songs, indoor and outdoor games, animal stories, and fables.

The functions of these stories, according to one participant, are "to teach kids how to socialize, to make critical thinkers, learn manners, and to entertain. Riddles, for instance, help children to think critically” (Participant: NGO Member). Another intimated that storytelling is primarily didactic in nature. Children are expected to attend carefully during storytelling sessions, right up to the point that the message is made clear:

Grandparents are more willing than parents to tell stories to children. When a grandparent tells a story, children sit around her/him and listen. Usually they sit rounding the fireplace in home. When the teller tells orally from his/her memory, children listen with strict discipline. They can smile, gesture, and even laugh. But they do not shout, move from place to place, and push each other. They listen until the teller finishes and tells message of the story. (Participant: Professor of Childhood Studies)

Participants identified the tellers of these stories as family and community members, including grandmothers, mothers, fathers, uncles, aunts, and neighbours. One participant remarked that siblings also tell the stories to one another, a point that is also emphasized by Jirata (2013) in his work on the oral tradition among the Guji-Oromo in Southern Ethiopia. Most remarked that the stories they recall were told orally from memory, regularly in the evening before bed. One reported hearing stories through radio and television, observing "there was a popular storyteller called Ababa Tesfaye on a TV children's show in my time” (Participant: Publisher).

Another participant, a published Ethiopian YA author who responded to our questions via email, captured the richness of storytelling sessions by noting the different environments in which his mother and father orated:

My father came from an Oromo family and he used to tell us about his home town, and my mother came from Amhara family and she used to tell us about her home town.

In Ethiopia extended coffee ceremony is common and neighbors are called as most house wives are around and find excuses to start telling about it. Sometimes my 
mother speaks about the same story again and again. I had a very strong grandmother-even neighbors were afraid of her. Most believed she was more than 100 years old. She was like a legend. My mother told stories about her grandmother-passed away at 118 years old. Unsure though as no birth certificatescould get clues of her age by what she spoke about (historically). Even men were afraid of her. She was very logical. She was part of a relatively well off countryside family. She was very bossy and supervised the men over their work. She was ahead of her time by assuming the responsibility herself for men's work and anyone's work. She remains center topic of stories today.

My father had a business and my siblings and I used to go to where the restaurant business is located. He used to tell stories about his home town not necessarily for us but for customers and others. Then we used to listen what he had to say. Father was Oromo- - when he came to the city he suffered exploitation. He started a restaurant business in Addis and was forced to change his name to Amharic to get customers. His wife was Amharic - at the time, this was a cultural no-no to give a daughter to an Oromo man. From my father's stories I learned about things more indirectly than directly as he wasn't necessarily talking to me but to his customers and friends and I would be around pretending to play but also listening. (Participant: Ethiopian Writer; no editorial changes have been made to these notes)

Notably, in keeping with the Ecological Systems Theory discussed earlier, which stresses the immediacy and import of the microsystem, the stories alluded to here are of hometowns and important people therein. Over the lengthy process of preparing coffee-roasting, grinding, boiling, filtering, pouring - the women "find excuses to start telling about it," the neuter pronoun here presumably referring to the recurring story of the legendary grandmother and her prescient behaviours that pushed the boundaries of gender roles. The story is not explicitly didactic and formal, as is the case in another participant's earlier description of children sitting attentively and waiting for the "message." Nor are the father's stories examples of direct instruction specifically intended for children; rather, children glean from these adult stories by eavesdropping while pretending to play.

If we view emergent and early reading materials as most appropriate when they reflect the microsystem, then it stands to reason that initial efforts at publishing children's literature in Ethiopia have drawn on the stories of the oral tradition commonly told in the home and community. When we asked our participants to list appropriate subjects or topics for young children's books, they proposed that literature for early reading should be about animals, the environment or surroundings (e.g., trees, rivers, etc.), holidays, "people in the localities," stories with morals, and "the common story topics." Regarding to the last suggestion, the participant in question named several Ethiopian fables that are recognizable as part of the oral tradition, including a biblical tale: "The Monkey and the Lion," "The Wise Man and Foolish Man,” and "The Clever Children.”

In writing about the oral tradition of the Guji-Oromo in southern Ethiopia, Jirata (2013) notes:

The concept of "oral practice" signifies oral tradition as comprising cultural genres that include myths, legends, folktales, jokes, proverbs, riddles, chants, blessings, curses, insults, folk songs and folk beliefs. The concept of “oral process” denotes oral 
tradition as events of social interaction and entails performances such storytelling, riddling, singing, dancing, joking, and chanting. Thus, oral tradition can be understood as cultural practices produced and reproduced through oral interactions. (p. 4)

Given this complexity, story forms for very young children, which by necessity are orally transmitted, are regularly the last to make the transition to writing in any culture and are still deemed nascent in many traditions of writing (e.g., Salisbury \& Styles, 2012). A reticence to render such oral practices into writing in any context stems at least partially from the fact that performative elements are difficult, if not impossible, to transmediate. The bridge from oral to written forms is made in children's books to some degree through a reliance on illustration to support and extend verbal content. This multimodal element of children's texts inevitably becomes a factor in the cost and ease of their production, both in print and digital environments. In the next section, we discuss several initiatives having an impact on access to early storybooks in Ethiopia.

\section{Digital Texts for Young Readers in Ethiopia}

As noted earlier, we hoped to plan a follow-up focus group session with our seven participants at Addis Ababa University in May, 2016; however, we were asked by the Dean to open the session to all faculty and students, and to convert the format to a more formal presentation on the production of digital books for early literacy in Ethiopia. Thirteen faculty and graduate students - in fields related to education and early childhood development-along with one NGO representative attended our May, 2016 workshop, "Consideration for the Production of Digital Books for Early Literacy in Majority World Contexts." In this presentation, we contemplated the ways literacy is being fostered, particularly in reference to the lack of readily available children's storybooks in Ethiopian indigenous languages. We also introduced three approaches to digital access that may lead to increased availability of early reading materials: (1) the International Children's Digital Library (ICDL); (2) the CODE Ethiopia Digital Books and Family Literacy Project; and (3) two crowdsourcing projects aimed at generating large multilingual digital corporanamely, Bloom Library and the African Storybook Project. Because the seminar room did not have connectivity, we presented all these projects as screen captures via a data projector. Below is a discussion of these projects in consideration of the responses from our workshop participant group.

The International Children's Digital Library (ICDL). The ICDL is an open-access curated collection of books that is primarily designed as a read-only platform. The ICDL goal, as stated on their website,

is to build a collection ... . that represents outstanding historical and contemporary books from throughout the world. Ultimately, the Foundation aspires to have every culture and language represented so that every child can know and appreciate the riches of children's literature from the world community. (International Children's Digital Library, 2017, para. 3) 
With 4,619 volumes in 59 languages, this project, having launched in November 2002, is about halfway to the stated goal of collecting 10,000 volumes in 100 languages (Druin et al., 2003; ICDL, 2017). Users are not invited to author stories, although they can add metadata to existing stories in the form of keyword tags. The ICDL Collection Development Policy (2005) makes clear that the primary focus is making available existing published volumes that are

- currently available in print and within copyright;

- out of print but within the copyright protection of the country in which they were published; or

- freely available in the public domain; there is no explicit solicitation for new materials. (International Children’s Digital Library, 2005)

In other words, this is primarily a print digitization project geared toward creating an open educational resource in the form of a digital corpus of previously published children's books in multiple languages.

The ICDL was prescient in terms of recognizing the need for a resource of this type; however, the requirement of negotiating copyright for most of the volumes added slows the growth of the collection - at a time when there is immediate need for early reading materials in some contexts. Additionally, by collecting already published work, the project is not aimed at the root problem discussed earlier - that there are few if any published storybooks in many languages used as a $\mathrm{MoI}$ in early education within and beyond Ethiopia. At the time of writing this paper, there were only two books listed by country as "Ethiopian" in the ICDL. Both—Fafi's Sheep and Lion's Tale - are traditional stories in Amharic that were originally published (in 2005 and 2006, respectively) by the Ethiopian Books for Children and Educational Foundation.

The CODE Ethiopia eBooks and Family Literacy Project. The second project we introduced was the CODE Ethiopia eBooks and Family Literacy Project. This began as a small-scale pilot, intended to complement national reform in education aimed at improving access and equity in early childhood care and education (Ethiopian Ministry of Education, 2016). The project initially targeted children aged 3 to 6 and their families in three rural areas where appropriate reading materials for the target group were unavailable. The primary objectives were to develop culturally and linguistically meaningful early reading materials written and illustrated by local writers and artists; to provide access to and guided experience with the texts in a family literacy program; and to invite communities to write stories relevant to their contexts, thereby fostering an interest in the writing of stories within communities (Abebe, 2015; Asselin, Dorion, \& Abebe, 2015; CODE Ethiopia, 2015).

Ethiopia-based librarians, writers, and CODE Ethiopia members initially selected six stories common to the oral tradition. Abebe (2015) notes that these were made available in two local languages, Amharic and Afaan Oromo, and that the themes of the stories "related to animals, school life, and friendship" (n.p.). Notably, most are moral or religious tales with a strong didactic element. Colonial influence in the Ethiopian oral tradition is also evident in the selection of Wondime Yakob (Brother Jacob or Frère Jacques), described on the project site as the "Amharic version" of the well known French nursery rhyme with a melody that is "almost the same as the French one" (CODE Ethiopia, 2015). 
Although the rhyme is heavily adapted to the point that it is dissimilar to the original rhyme in most respects, the story describes the morning routine of a brother and sister who wake each other up and later go to school to acquire knowledge.

Although this CODE Ethiopia pilot work was initially couched as a digital book project, the book production model is consistent with contemporary approaches to print publication. CODE Ethiopia deemed a dual-platform approach a necessity-that is, all books must be produced in such a way that multiple copies of each text can be distributed in either print or digital formats. In this respect, a conventional design approach for Western monographs is employed: Books are construed as artefacts with a title page, front matter, and multiple pages featuring text and image with margins (see Figure 2). Printed versions can be produced quickly — for home reading or if hardware or power fails—via photocopier (see Figure 3). Given this model, there is limited opportunity to explore the multimodal affordances of digital platforms-affordances such as audio and video features that might be better suited to a setting with a strong oral tradition. Instead, the bulk of digital materials produced might be described as "print adaptations" (Joyce, 1996). Both print and digital versions of the books produced in the context of this project are distributed under a Creative Commons Attribution-NonCommercial license.

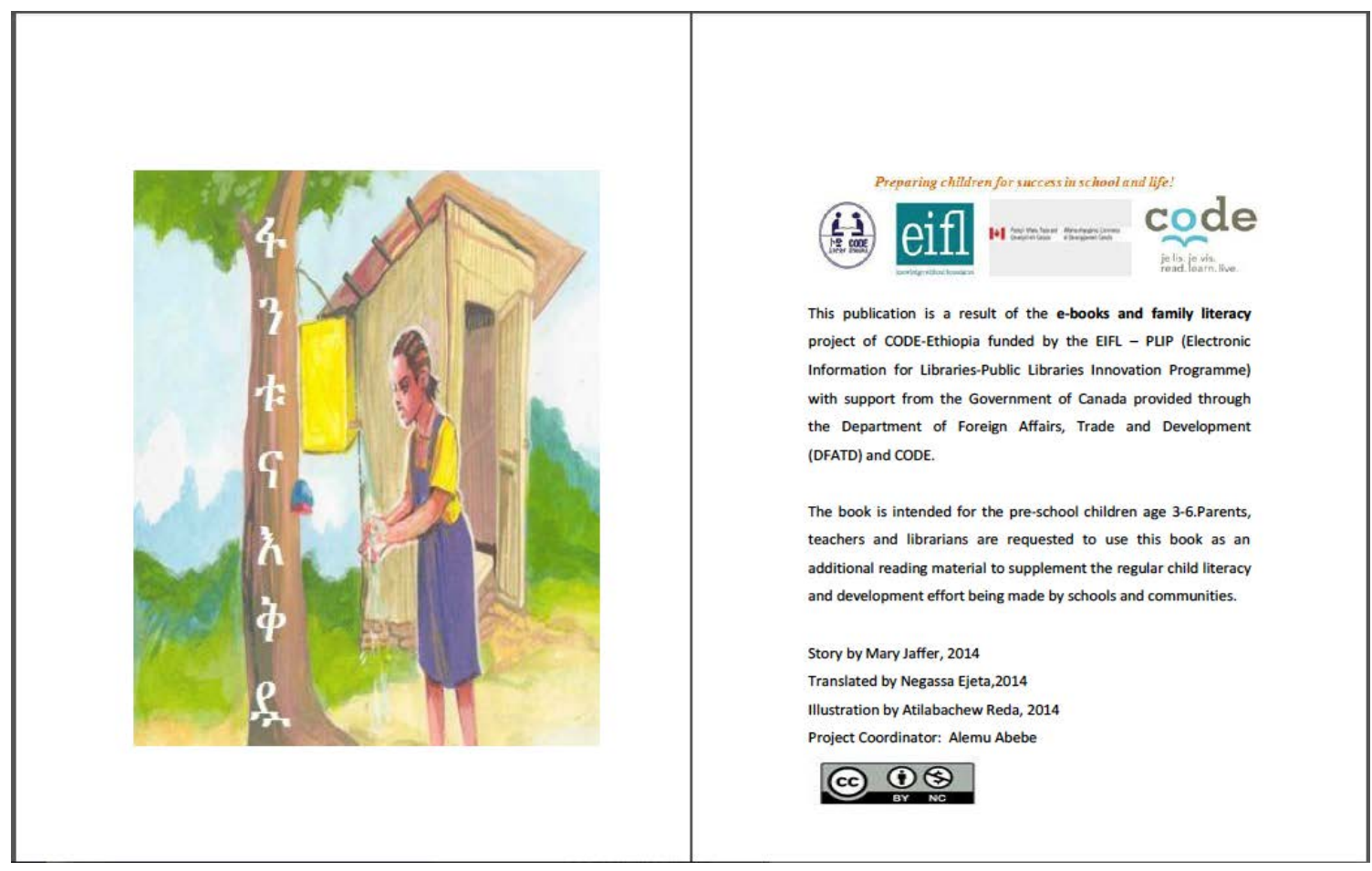

Figure 2. Fantu ena ekiduwa (Fantu and her Plan) is the story of a Grade 1 student who tells about her daily activities. 


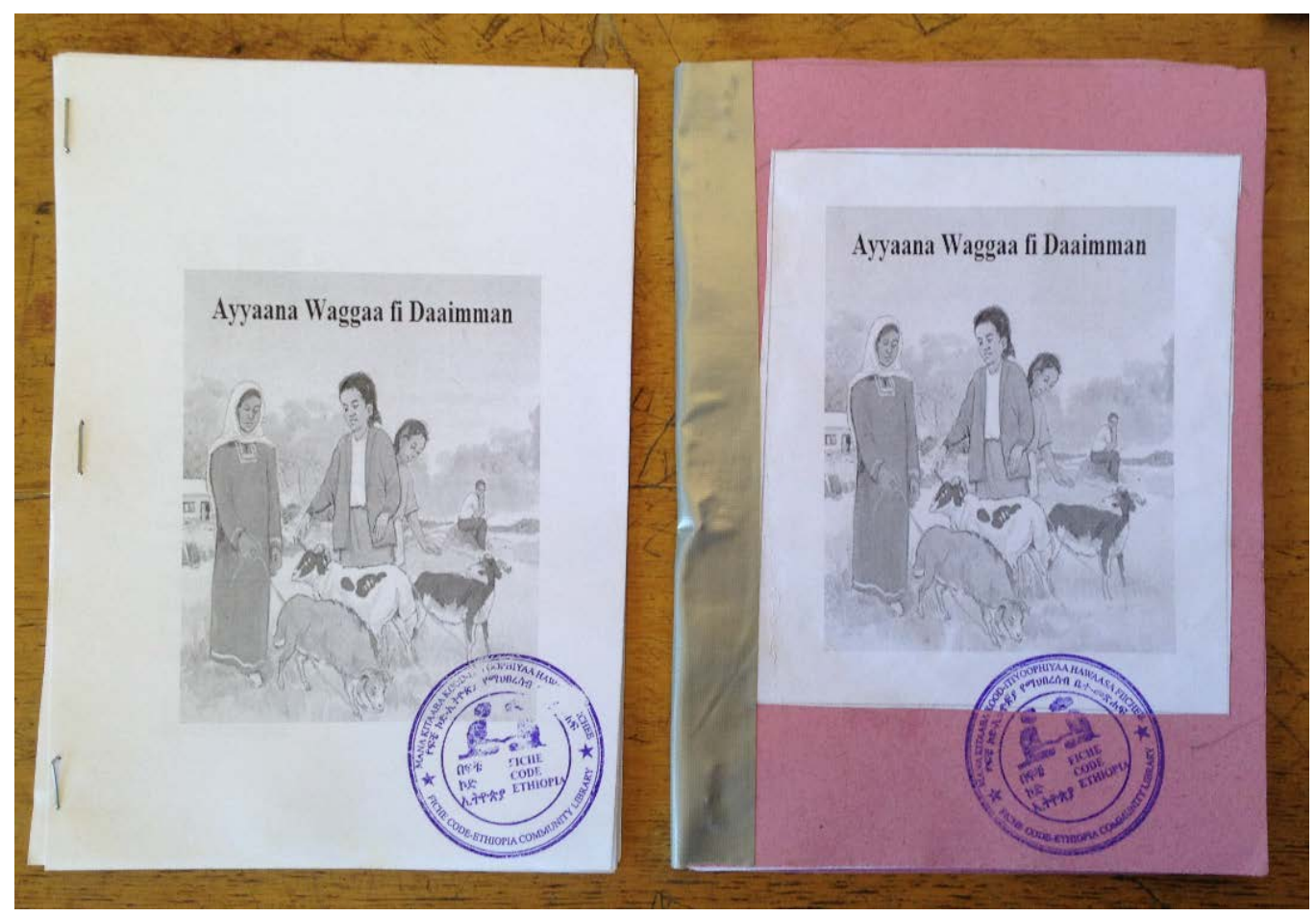

Figure 3. Printed copies of the Afaan Oromo version of New Year and Children (Ayyaana Waggaa fi Daaimman).

Beyond production of the six books, there was a focus on building a corpus of context-sensitive texts by inviting each of the three communities involved in the pilot to contribute two stories commonly told in their own contexts. CODE Ethiopia selected and edited three of the resulting stories and had them illustrated by the project illustrator, Atilabachew Reda. Original books from this project, along with the three contributed by communities, have now been translated into six Ethiopian languages. Each translation was treated with extreme care for sensitivity to context, including attendance to local dialects and customs, as well as reworking of illustrations to reflect local settings. Consider, for example, three unique covers for the Amharic, Afaan Oromo, and Somali versions of New Year and Children (Figures 4-6). The nine books have been prepared in PDF formats and are loaded onto tablets for use in ongoing literacy projects managed by CODE Ethiopia. They have also been acquired by the African Storybook Project. Those who attended the session commented favourably on this project and the demonstrable feasibility of the approach with regard to future literacy and collection-building endeavours. 


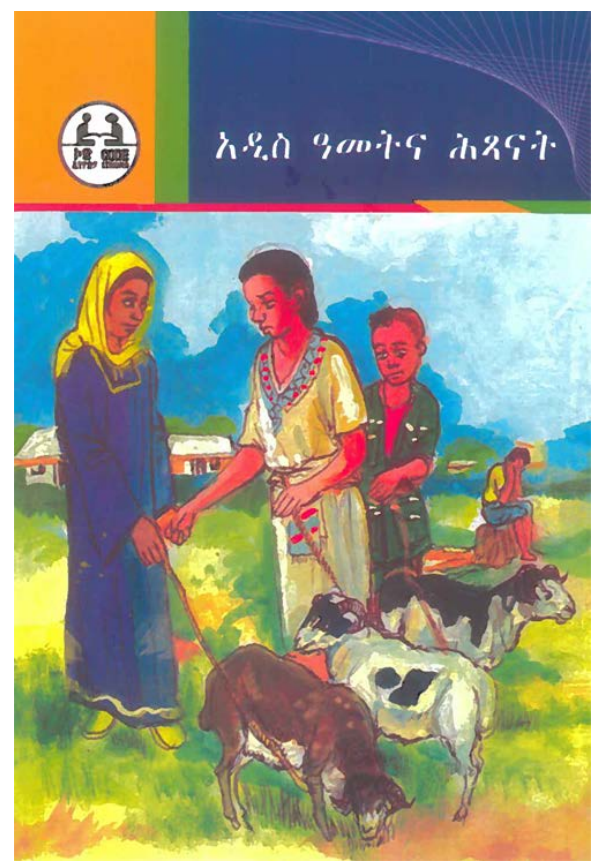

Figure 4. Amharic version of New Year and Children, with cover reflecting traditional dress of the Amhara Region.

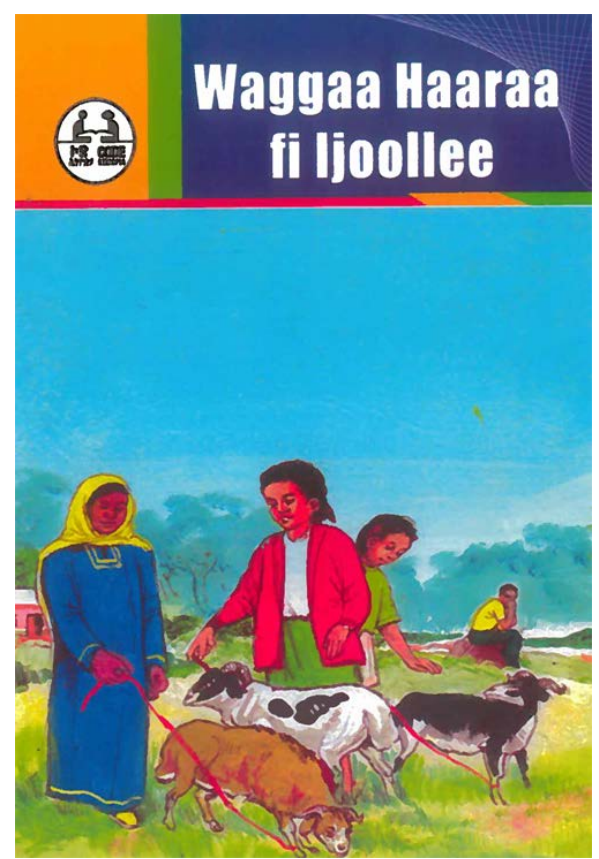

Figure 5. One of two (given the unique dialects of this language) Oromo versions of New Year and Children, with a cover reflecting dress common in the Dire Dawa area. 


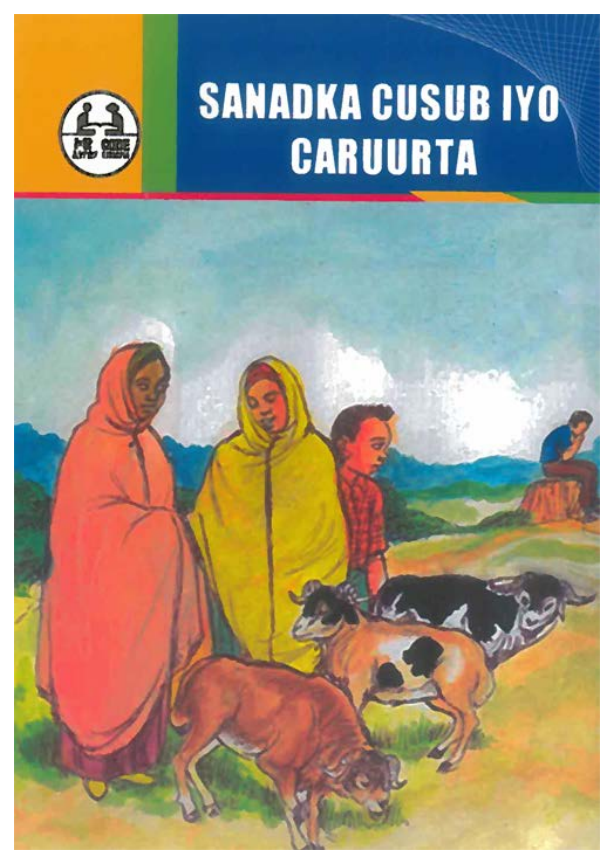

Figure 6. Somali version of New Year and Children, with cover reflecting Muslim dress common in the Somali Region.

Outsourcing to the crowd: Bloom Library and the African Storybook Project. The third and fourth approach we introduced were crowdsourcing initiatives that harness the collective wisdom of communities in the quest to develop large corpora rapidlyspecifically, Bloom Library and the African Storybook Project (ASb). Both projects allow users to read, download, translate, and create stories. Like ICDL, Bloom has a global scope, while ASb has an African focus. Bloom sets out the problem that both projects aim to address on its splash page, observing that literacy educators are regularly faced with too few books in localized indigenous language settings to successfully foster literacy:

We know that it takes stacks of titles to make reading worthwhile and give the practice needed to develop true literacy. The problem has been who will make all those books? How will we find the time? Where will we get the content? So we settle for the possible and hope for the best. (Bloom Library, 2017, para. 1)

Therefore, a key challenge addressed by such projects - similar to the CODE Ethiopia project-is building interest in story writing and the capacity for bookmaking in local communities where collections of reading materials are not available. To this end, "Bloom dramatically lowers the bar" by providing simple-to-use software and a range of book templates- "so that many more people can get involved in building a large collection of local language books” (Bloom Library, 2017).

Data from the Internet Archive show that Bloom Library and ASb were launched at roughly the same time. (The Archive shows Bloom Library had launched at bloomlibrary.org by July, 2014; meanwhile, by September, 2013, ASb had launched a preliminary site announcing its initiative at africanstorybook.org, and provided a site with functionality for users by May, 2014.) Both projects have since collected many volumes1,151 in the case of Bloom Library and almost 4,000 in the case of ASb. (Unlike ICDL and 
Bloom Library, there is not a readily apparent count of the total number of books on ASb, although up until 1 April, 2017, it was possible to estimate-based on summing the totals in each category and assuming books did not regularly appear in multiple categories.)

The slower growth of Bloom Library despite its global scope is likely a matter of accessibility. Bloom Library requires users to download software before reading and uploading stories, and this software is only available for PC and Linux standalone computers. For creators, Bloom Library also recommends the installation of "The Art of Reading," a curated collection of line drawings, fonts, and a typing script for creators who do not have a way to type their own language. The fact that a download is required to create and read — and that there is no compatibility for the Mac OS — undoubtedly reduces the number of users of and contributors to the Bloom Library. Nevertheless, this approach evidently does have benefits; for instance, it offers a way for users to create offline, which is a major consideration for settings with unreliable Internet access. ASb, on the other hand, has circumvented such platform wars by opting for a web application based on JavaScript and hosted in a Drupal shell. No registration or local software is required to read or download ASb books. The only potential impediment to submit or version (i.e., translate) a story is the creation of an account. Thus the ASb collection, having removed all barriers to access other than connectivity, is growing most rapidly of all. It is also noteworthy that strong promotion of translation or versioning by the ASb has contributed to the rapid growth of its corpus, a point to which we will return.

Both the Bloom Library and ASb growth rates eclipse that of the projects discussed earlier (recall that it has taken the ICDL 15 years to collect 4,619 volumes). Clearly the "possible" described by Bloom Library, in opting for crowdsourcing over curation, is coming to fruition; what is less clear is whether their "hope for the best" in taking this approach is being realized. As Porcello and Hsi (2013) note in speaking of the variable quality of open educational resources (OER), there are benefits and drawbacks to crowdsourcing approaches:

On one hand, collections using crowdsourcing allow a wide range of online users to contribute, choosing their own descriptions and keywords to catalog, review, and manage OERs. This can produce large and loose collections. Although dedicated users from the resulting online communities might be more willing to detail their instructional experiences and personal connections to OERs, overall quality may be quite variable. On the other hand, having professional staff with disciplinary expertise populate, catalog, and maintain curated collections usually results in finetuned, coherent, and smaller collections. Although these collections grow more slowly, often with less vocal user communities, they can quickly respond to new quality or educational standards. (Porcello \& Hsi, 2013, p. 240)

As we considered the possibilities of the crowdsourcing projects for the Ethiopian context with those in attendance, the question of reimagining texts for different contexts through versioning and adaptation became a main point of interest.

At the time of our presentation in Addis Ababa, there were no volumes in Ethiopian languages in the Bloom Library collection; this continues to be the case. There was, however, a growing collection of books on ASb. As noted earlier, connectivity was unavailable for our workshop, so we selected four Amharic books as examples and 
included representative screen captures within our presentation. These were as follows: (1) Fantu and her Plan, a CODE Ethiopia book with which the group was familiar; (2) How Many?, a counting book with simple sketches of insects, birds, and mammals; (3) The Girl Who Got Rich, a moral story about two poor, hungry sisters who separately encounter a leper woman with magical powers and receive different fates in accordance with their treatment of her; and (4) I Like to Read, a simple text for early readers about a boy who enjoys reading and wanders about his home trying to find family members with whom he can share his story.

Beyond the CODE Ethiopia text, all of the above books are versioned from other languages not indigenous to Ethiopia. The counting book, How Many?-written by Clare Verbeek, Thembani Dladla, and Zanele Buthelezi and illustrated by Sandra McDougallfirst appeared in Zulu. It was originally produced through the Seed Books project of the School of Education and Development and the Centre for Adult Education at the University of KwaZulu-Natal, South Africa. The Girl Who Got Rich is by Ugandan author Salaama Wanale, written in Lumasaaba and versioned by the same author to Amharic. The illustrations are attributed to "Mango Tree," which is apparently "Mango Tree Educational Enterprises," a Ugandan educational consulting firm (L. Doherty, personal communication, 14 March 2017). Finally, I Like to Read is written by Letta Machogo in Sepedi, with illustrations by Wiehan de Jager, both of South Africa. The Amharic translation is by Sehin Tefera and Mezemir Girma.

I Like to Read: One example of versioning for the Ethiopian context. Of the four texts, the first three drew little in the way of comment or response. The group was familiar with the CODE Ethiopia text. The second two texts, How Many? and The Girl Who Got Rich, depicted items or settings that were familiar (local animals in the first case and the traditional tukal homes, common in East Africa, in the latter). The fourth text, I Like to Read, drew an audible gasp of surprise. What garnered the group's attention was not the story, but the illustrations. The cover and first page spread show a smartly dressed boy in a well-appointed home. He is seated in an orange upholstered chair, next to which is a leafy plant in a large vase. A landscape painting hangs on the vibrant green wall behind him, and it appears there is wall-to-wall carpeting on the floor. "I like to read," or "I like reading," declares the boy (see Figure 7). On the second page spread he stands at the door of his baby sister's room. He is searching for someone with whom he can read. The baby is sleeping soundly in a white crib, a large soother in her mouth. A mobile comprised of smiling stars hangs above the crib. The walls appear to be papered in pink, with a cloud wall appliqué positioned next to the crib. "Who can I read to?” the boy asks (see Figure 8). 


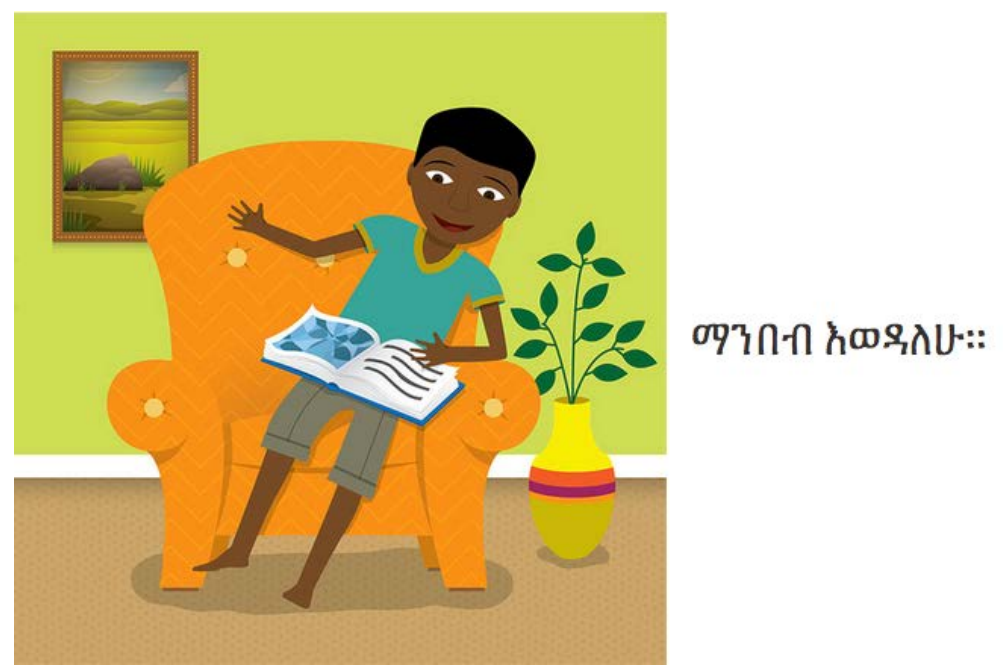

Figure 7. I Like to Read, first page spread.

તળ૧૩ તએનીની?

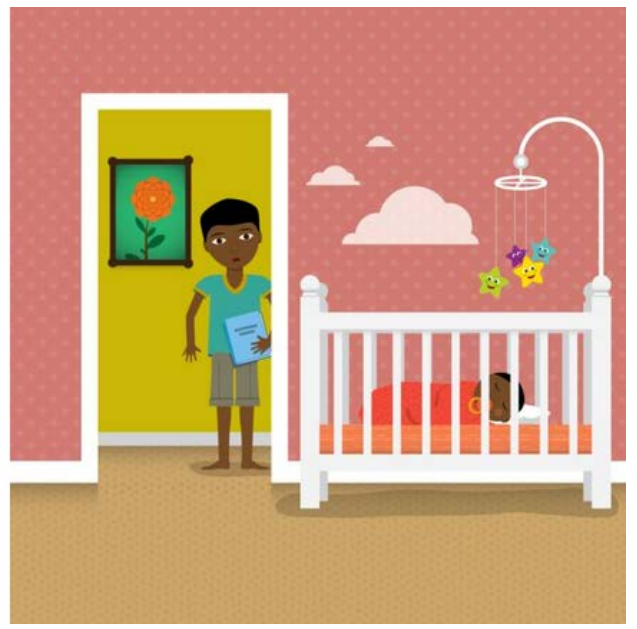

Figure 8. I like to Read, second page spread.

Those in attendance were not familiar with the crowdsourcing approach of the ASb that results in stories migrating across contexts through versioning or adaptation. At first glance, it would be easy for any reader to overlook metadata and surmise that a story written in Amharic should be of Ethiopian origin. But the images, so clearly not reflecting Ethiopian settings, made the book untenable and created discomfort.

The illustrations are by Wiehan de Jager, a designer from Cape Town, South Africa. They reflect mixed design elements, mostly of European origin, from Colonial Revival Style (e.g., machine-milled trim and moulding) to Mid-Century Modern (e.g., simple lines, geometric patterns, and aesthetic contrast). In Ethiopian homes, however, such design features - wallpaper, mouldings, carpeting, mobiles, cribs, and so on-are rare. Many homes, especially in rural areas, are "constructed with mud-plastered wooden walls and grass roofs," and a single room may serve for "sleeping, keeping all household belongings, cooking and dining, keeping warm by burning wood, and also for tethering domestic animals at night” (Animut, Balkew, \& Lindtjørn, 2013, p. 2). A 2011 study showed that $85 \%$ of Ethiopian homes have flooring of earth and sand or dung, and that $70 \%$ use one room for sleeping. Family beds are the norm. Only 19\% of rural households have piped 
water and 5\% of rural households have electricity. Toilets are often shared among several households, even in urban settings (Central Statistical Agency of Ethiopia, 2012, p. 16).

This reality stands in contrast to the domestic spaces pictured by Wiehan de Jager in I Like to Read. He depicts the protagonist wandering through a home comprised of multiple rooms-a living room, nursery, and kitchen — before venturing out to the front of the house, where he finds men fixing a car on a paved driveway (Figure 9). This last detail is also incongruent with local context, in consideration of the fact that Ethiopia stands near the bottom of the cars-per-capita list globally at 2 or 3 vehicles per 1,000 people (e.g., Deloitte, 2016, p. 7).

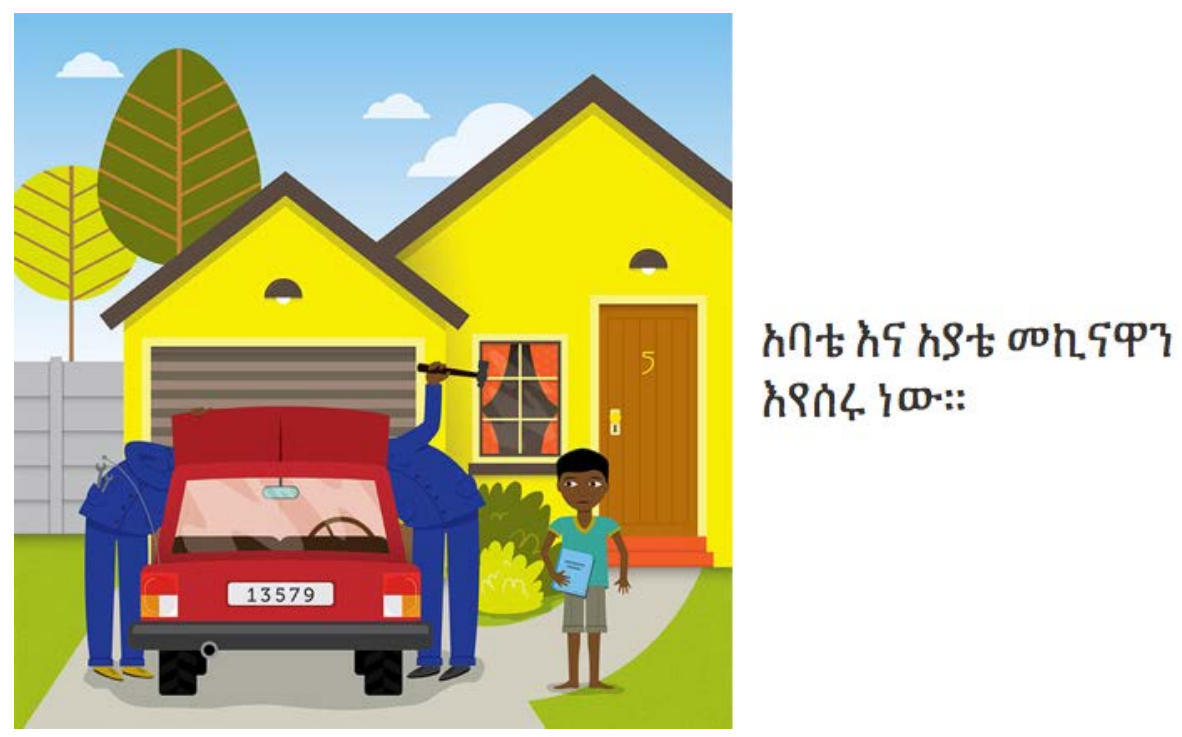

Figure 9. I Like to Read, seventh page spread.

Illustrations from I Like to Read provoked comment among presentation attendees about the disjuncture between such images and the reality of Ethiopian settings. Participants discussed the challenge of finding a balance between generating culturally sensitive reading materials and steering clear of ethnocentrism. One individual emphasized that texts should be reflective of and consistent with the particular social context of the intended readership. Another agreed, stipulating that when children learn to read, it must be with culturally relevant materials. There was a clear aversion among many present to the concept of generic "readers" (texts designed for learning to read) in contrast to authentic, context specific stories. Yet one person presented another perspective, suggesting that stories serve as means of socialization and can be viewed as vehicles of ethnocentrism. This prompted the question: "To what extent should or can stories be bias or culture-free?” One speaker argued for the merit of stories designed for literacy learning that are transferable across cultures, while another suggested stories such as I Like to Read are not artefacts of bias but evidence of Ethiopia's diversity. Still another claimed that ethnocentrism is systemic and that an exclusive focus on culturally sensitive texts would further promote this perspective.

In considering these responses, it is important to note that the presentation attendees were unaware the story was versioned rather than an original work in Amharic. Evaluating books from various projects was not the focus of the session; the aim, rather, was to put forth more broadly the affordances of digital means of knowledge mobilization for early 
literacy education in the Ethiopian context. In making book selections, therefore, we did not attend to which stories were versioned and which were originally in Amharic, intending merely to flick through screen captures to show that a number of Amharic books were available and then to invite attendees to look at the ASb site themselves (a plan the lack of connectivity in our seminar room prevented). Ultimately, however, we would suggest it is very likely that many ASb readers who make keyword searches for stories in particular target languages will not be aware if they encounter "unique" or "versioned" stories. Without the presence of clear statements indicating the versioning history of the narrative-story biographies, if you will-it would be easy for those readers not attuned to the way in which the corpus is produced to overlook metadata and, like our audience, find an unexpected disjuncture between the context suggested by the text and the context suggested by the illustrations.

In a report on the African Storybook Project, Welch and Glennie (2016a) state that versioned stories make up the bulk of the corpus. End-of-month statistics from January through June 2015 show the ratio of the number of versioned stories to the number of unique stories is consistently greater than 3 to 1 (p. 202). I Like to Read alone had been versioned 35 times at the time of the writing of this paper into a range of languages indigenous to Africa and otherwise. Furthermore, the story is typically translated not from the Sepedi version, which is given the status of being the original story, but from one of two English instantiations. Both are also by the story author, Letta Machoga, but have slight lexical variations: I Like to Read and I Love to Read. (Notably, our analysis of the versions of I Like to Read was completed before changes to the ASb interface, effected in early April 2017, buried the site metadata, at least for the moment, to the point that it is no longer possible to trace the versioning history of stories.)

Welch and Glennie (2016a) explain that the ASb has actively pursued translation as an effective way to build the corpus, noting that each story can be translated into "multiple languages for no cost" and that "workshops with local language speakers have proved very effective” (p. 203). They remark in particular on a successful translation workshop with 24 participants that produced "65 versions of seven existing stories" (p. 203). In many ways, this is an exciting initiative. In an ASb blog post on versioning, Dorcus Wepukhulu, Kenya-based coordinator for the ASb, observes that translation workshop participants become involved in complex discussions about matters of translation, pondering appropriateness to context, text level, and so on. They consider, for example, whether they are engaging in translation or adaptation, depending on the extent of the nature of changes to the text (e.g., whether the aim is to stay as close to original narrative as possible or to adapt for context suitability). They grapple with dialects and regional preferences, as well as with the appropriateness of oral or written constructions (Wepukhulu, 2016). The language work described by Wepukhulu is clearly careful, but the matter of how illustrations are managed through the process of versioning is worrisome. Wepukhulu ends her writing pondering this dilemma:

There is the issue of whether I can adapt the text and retain the illustrations or could I adapt illustrations and retain the text? At the moment it is not possible to do the latter. How can I adapt actions/events in a story without having to adapt illustrations ... ? (Wepukhulu, 2016, n.p.) 
As we have seen in consideration of I Like to Read, the question is broader than this. Even if the translation reflects the source very closely - that is to say, if actions and events are unaltered to the extent that this is possible in translation - a failure to bring illustrations in line with the intended context could derail meaning for young readers.

In texts for emergent and early readers, illustrations are integral to meaning making. There is much research in this area that is beyond the scope of this paper; suffice it to say that picture books work through the integration of visual and verbal meanings (e.g., Painter, Martin, \& Unsworth, 2013). Emergent readers use pictures as primary clues to construct meaning and may benefit from texts in which images reinforce the verbal meaning (e.g., Anderson, Hiebert, Scott \& Wilkenson, 1985; Clay, 1993; Harste, Woodward, \& Burke, 1984). Books for more advanced readers may evidence increasingly complex uses of illustration to reinforce, extend, or interrogate the verbal aspects of the text (Evans, 2015). In spite of a wealth of knowledge about the critical role of images in children's literature, both crowdsourcing projects appear to privilege the verbal over the visual elements by relying on stock illustrations or promoting image reuse. Bloom Library, a project of global scale, offers a curated collection of line drawings, The Art of Reading: "This free collection contains more than 10,000 line drawings suitable for use in reading materials” (Bloom Library, 2017). ASb has offered a cost-benefit analysis for image reuse:

An important additional dimension is that it is possible to produce these storybooks at a fraction of the cost of original titles because the illustrations are re-usable, and the digital tools exist for publishing of a translation in the same format. The African Storybook commissions high quality digital illustrations at an average cost of USD 100 per 12-page book. Each translation and adaptation makes use of the same illustrations. So the initial investment in the book is spread across the 20 or more versions of the book that are created. In addition, the professional illustrations are stored in the African Storybook image bank and can be used not only for translations and adaptations of a storybook, but combined to create new storybooks. (Welch \& Glennie, 2016b, p. 4)

Although ASb project members report that the stories are "written and illustrated by Africans" (Stranger-Johannessen, 2017, p. 27), it is not clear that this is in fact the case. Listed illustrators for some books, for instance, are widely accessible image banks and Internet image search engines such as Google. Even in the case that illustrators and writers are African, the question remains as to whether these illustrations and writings are transportable across the exceedingly diverse continent that is Africa, as we have seen in the case of I Like to Read. Are the drawings of Weihan De Jager, a white designer and specialist in corporate branding living in South Africa, relevant in settings associated with the many languages into which the book has now been translated? Suggesting this should be the case, as intimated in the cost analysis above, seems dangerously close to the sort of one-sizefits-all racial, ethnic, territorial or geopolitical essentialism that has long plagued Africaputting what is clearly a valuable project in danger of being cast as an engine of neocolonialism. Most certainly this cost-saving strategy runs counter to the ASb goal: "Children need to have books in a familiar language, with stories that reflect their context and experience, as well as their hopes for the future, so that they can connect with them emotionally” (Welch \& Glennie, 2016a, p. 195). 
It is not our intent to dismiss the important work of Bloom Library or the ASb, but rather to enter into a conversation about the benefits and drawbacks of various methodologies for building a corpus of early reading materials that is highly sensitive to cultural context. While template-driven production approaches, crowdsourcing, open licences, and versioning may build a corpus quickly and at a low cost, they are all Western models of knowledge production and mobilization that require careful navigation when used for the generation of culturally sensitive literary materials for primarily oral contexts. Literary culture, children's literature, and mass literacy has developed over hundreds of years in the global North; ultimately, we wonder, what is the effect of accelerating the process in particular settings with newly literate populations? Evidently there is much work to be done in examining the limitations and affordances of various models for this proposed work.

\section{Conclusion}

Many have represented low literacy rates in majority world contexts as a crisis, and a range of literacy programs have been initiated in response-some of which we have discussed in this paper. We view these programs as exceedingly valuable in many ways. We also recognize, however, even as we acknowledge our involvement in such projects (two of the authors of this paper spearheaded the CODE Ethiopia project described earlier), that we must continue to engage in critical conversations about the impacts-both positive and negative - of various interventions. As Graff (1979) rightly observed almost four decades ago, it is not a given that literacy translates to economic, social, and cultural success. On the contrary, literacy is often used by those in authority as the "vehicle for the efficient training of the population and the maintenance of hegemony" (Graff, 1979, 236). As Luke (2008) has observed, "in contemporary human capital models of education," advocated by institutions such as UNESCO, "levels of literacy continue to be taken as robust predictors of economic 'take-off,' industrial development and, indeed, socioeconomic and political enfranchisement” (p. 247). Wickens and Sandlin (2007) suggest that in spite of the fact that the literacy community is fully aware that literacy is inherently political — and that many current programs continue social control - there is a persistent suggestion that literacy education is vital in all parts of the globe, even in contexts with strong oral traditions. Thus, its absence is met with panicked movements to address a perceived lack as quickly as possible.

Ultimately, in reference to programs of potential relevance in the Ethiopian context, we ask the following questions: What are the implications of initiatives that impose Western models of literacy in contexts with strong oral traditions? What is the long-term effect of rapid injection of literary materials on emergent communities of literary artists and illustrators in local contexts? What are the limitations of current approaches that lean toward template-driven, dual-platform publication and perhaps obscure the possibility of multimodal approaches? In contexts where the oral transmission of knowledge prevails, are there possibilities for more innovative, multimodal approaches that might harness the affordances of digital publication? None of these are easy questions, but they are vital as we consider conditions for inclusion and equity across multiple communities, languages, forums, and expressive modes within the Ethiopian context and beyond. 


\section{References}

Abebe, A. (2015). eBooks and family literacy programme. Retrieved from UNESCO website: http://litbase.uil.unesco.org/?menu=4\&programme=219

African Storybook Project. (2015). Retrieved from http://www.africanstorybook.org/

Anderson, R., Hiebert, E., Scott, J., \& Wilkenson, I. (1985). Becoming a nation of readers: The report of the commission on reading. Washington, D.C.: National Academy of Education.

Anderson, R. C., \& Pearson, P. D. (1984). A schema-theoretic view of basic processes in reading. In P. D. Pearson (Ed.), Handbook of Reading Research (pp. 255-291). New York, NY: Longman.

Animut, A., Balkew, M., \& Lindtjørn, B. (2013). Impact of housing condition on indoorbiting and indoor-resting Anopheles arabiensis density in a highland area, central Ethiopia. Malaria Journal, 12(1), n.p.

Asselin, M., Doiron, R., \& Abebe, A. (2015). Applying an ecological model and standards for library development to build literacy in rural Ethiopian communities. In B. A. Schultz-Jones \& D. Oberg (Eds.), Global action on school library guidelines (Vol. 167), (pp. 133-152). Berlin, Germany: De Gruyter Saur.

Bloom Library. (2017). Bloom library landing page. Retrieved from http://bloomlibrary.org/

Bronfenbrenner, U. (1979). The ecology of human development: Experiments by nature and design. Cambridge, MA: Harvard University Press.

Bronfenbrenner, U., \& Morris, P. A. (2007). The bioecological model of human development. In R. M. Lerner \& W. Damon (Eds.), Handbook of child psychology: Theoretical models of human development (Vol. 1, 6th ed., pp. 793828). Hoboken, NJ: Wiley. DOI: 10.1002/9780470147658.chpsy0114

Central Statistical Agency of Ethiopia. (2010). Population and housing census 2007 report, national. Retrieved from http://catalog.ihsn.org/index.php/catalog/3583/download/50086.

Central Statistical Agency of Ethiopia. (2012). Ethiopia demographic and health survey 2011. Addis Ababa, Ethiopia: Author. Retrieved from https://www.unicef.org/ethiopia/ET_2011_EDHS.pdf

Clay, M. (1993). An observation survey of early literacy achievement. Portsmouth, NH: Heinemann.

CODE Ethiopia. (2015). Community libraries supporting family literacy: Using digital books for preschool children. Retrieved from https://codeethiopiadigitalbooks.wordpress.com/

Cummins, J. (2001). Bilingual children's mother tongue: Why is it important for education? Sprogforum, 19, 15-20.

Deloitte (2016). Navigating the African automotive sector: Ethiopia, Kenya and Nigeria. Deloitte Africa Automotive Insights Series. Johannesburg, South Africa: Deloitte Africa. Retrieved from https://www2.deloitte.com/za/en/pages/manufacturing/articles/navigating-theafrican-automotive-sector--ethiopia--kenya-and-ni.html

Druin, A., Bederson, B., Weeks, A., Farber, A., Grosjean, J., Guha, M., Hourcade, J. Lee, J. Liao, S., Reuter, K., Rose, A., Takayama, Y., \& Zhang, L. (2003). The international children's digital library: Description and analysis of first use. First 
Monday, 8(5). Retrieved from

http://journals.uic.edu/ojs/index.php/fm/article/view/1050/970

Ethiopian Ministry of Education. (2016). Access and equity in early childhood care and education. Retrieved from http://www.moe.gov.et/general-education

Ethiopian Ministry of Finance and Economic Development. (2010.) Growth and Transformation Plan (GTP): 2010/11-2014/15. Retrievable from http://www.mofed.gov.et

Evan, J. (Ed.) (2015). Challenging and controversial picturebooks: Creative and critical responses to visual texts. London, UK: Routledge.

Fox, D. L., \& Short, K. G. (2003). Stories matter: The complexity of cultural authenticity in children's literature. Urbana, IL: National Council of Teachers of English.

Getachew, A., \& Derib, A. (2006). Language policy in Ethiopia: History and current trends. Ethiopian Journal of Education and Sciences, 2(1), 37-62.

Government of Ethiopia. (1994). Education and training policy. Addis Ababa: Federal Democratic Republic Government of Ethiopia. Retrieved from http://www.moe.gov.et/documents/20182/42694/Ethiopia+Education+and+Traini ng+Policy.pdf/0ce903d9-3ec7-43fc-9470-29655d9864d3

Graff, H. J. (1979). The literacy myth: Literacy and social structure in the nineteenthcentury city. New York, NY: Academic Press.

Harste, J. C., Woodward, V. A., \& Burke, C. L. (1984). Language stories \& literacy lessons. Portsmouth, N.H: Heinemann Educational Books.

Heugh, K., Benson, C., Bogale, B., \& Yohannes, M. A. G. (2007). Final report: Study on medium of instruction in primary schools in Ethiopia. Commissioned by the Ethiopian Ministry of Education. Mother Tongue Based-Multilingual Education Network. Retrieved from http://mlenetwork.org/sites/default/files/Final\%20report\%20study\%20on\%20Med ium\%20of\%20Instruction\%20in\%20primary\%20schools\%20in\%20Ethiopia\%20\%20Heugh\%20et\%20al\%202007.pdf

International Children's Digital Library. (2005, March 7). International children's digital library collection development policy. Retrieved from http://en.childrenslibrary.org/about/collection.shtml

International Children’s Digital Library. (2017). International children’s digital library mission statement. Retrieved from http://en.childrenslibrary.org/about/mission.shtml

Jirata, T. J. (2013). Children and oral tradition among the Guji-Oromo in Southern Ethiopia. (Unpublished doctoral dissertation.) Norwegian University of Science and Technology, Trondheim, Norway. Retrieved from https://brage.bibsys.no/xmlui/handle/11250/269081

Joshi, R., \& Verspoor, A. (2012). Secondary education in Ethiopia: Supporting growth and transformation. Washington, D.C.: World Bank. DOI:10.1596/978-0-82139727-5

Joyce, M. (1996). Of two minds: Hypertext pedagogy and poetics. Ann Arbor, MI: University of Michigan Press.

Kim, Y.-S. G., Boyle, H. N., Zuilkowski, S. S., \& Nakamura, P. (2016). Landscape report on early grade literacy. Washington, D.C.: United States Agency for International Development (USAID). 
Luke, A. (2008). On the situated and ambiguous effects of literacy. International Journal of Bilingual Education and Bilingualism, 11(2), 246-249.

McCann, J. C. (2001). Literacy, orality, and property: Church documents in Ethiopia. Cambridge, MA: MIT Press. DOI:10.1162/00221950152103919

Moll, L.C. \& Gonzalez, N. (1994). Lessons from research with language minority children. Journal of Reading Behaviour, 26, 439-456. Interdisciplinary History, 32(1), 81-88.

Moll, L. C., \& Greenberg, J. (1990). Creating zones of possibilities: Combining social contexts for instruction. In L. C. Moll (Ed.), Vygotsky and education: Instructional implications and applications of sociohistorical psychology (pp. 319-348). Cambridge, UK: Cambridge University Press.

Organization of African Unity. (1990). African charter on the rights and welfare of the child. Addis Ababa, Ethiopia: Organization of African Unity.

Painter, C., Martin, J. R., \& Unsworth, L. (2013). Reading visual narratives: Image analysis of children's picture books. Sheffield, England: Equinox Publishing.

Porcello, D., \& Hsi, S. (2013). Crowdsourcing and curating online education resources. Science, 341(6143), 240-241.

Salisbury, M., \& Styles, M. (2012). Children's picturebooks: The art of visual storytelling. London, UK: Laurence King Publishing.

Scelta, G. F., \& Quezzaire-Belle, P. (2001). The comparative origin and usage of the Ge'ez writing system of Ethiopia. Unpublished manuscript.

Smith, L. (2008). The politics of contemporary language policy in Ethiopia. Journal of Developing Societies, 24(2), 207-243.

Smith, J., \& Wiese, P. (2006). Authenticating children's literature: Raising cultural awareness with an inquiry-based project in a teacher education course. Teacher Education Quarterly, 33(2), 69-87.

Stranger-Johannessen, E. (2017). The African Storybook, teachers' resources, and pedagogical practices. International Journal of Educational Development, 52, 2636.

United Nations. (1989). Convention on the rights of the child. Retrieved from http://www.unicef.org/crc/

The United Nations Educational, Scientific and Cultural Organisation Institute of Statistics (UIS). (2008). International literacy statistics: A review of concepts, methodology and current data. Retrieved from

http://www.uis.unesco.org/Library/Documents/Literacyreport2008_en.pdf

The United Nations Educational, Scientific and Cultural Organisation Institute of Statistics (UIS). (2016). Ethiopia. Retrieved from http://uis.unesco.org/en/country/ET

United States Agency for International Development. (2017). Global reading network. Retrieved from https://globalreadingnetwork.net/about

Vujich, D. (2013). Policy and practice on language of instruction in Ethiopian schools findings from the young lives school survey. Young lives: An international study of childhood poverty. (Working Paper 108). Oxford, UK: Oxford Department of International Development. Retrieved from https://assets.publishing.service.gov.uk/media/57a08a21ed915d3cfd0005de/wp10 $\underline{8}$ _vujich_language-of-instruction.pdf 
Welch, T. \& Glennie, J. (2016a). Open educational resources for early literacy in Africa: The role of the African Storybook Initiative. In Miao, F., Mishra, S., McGreal, R., (Eds.), Open educational resources: Policy, costs, transformation (pp. 195-210). Paris, France: United Nations Educational, Scientific and Cultural Organization.

Welch, T., \& Glennie, J. (2016b, November). OER contributing to early literacy in Africa: Evidence from Saide's African Storybook. Commonwealth of Learning. Retrieved from http://oasis.col.org/handle/11599/2534

Wepukhulu, D. (2016, April 29). What are the issues in translating and versioning stories for early reading in local African languages? The African Storybook Project Blog. [Web log post]. Retrieved from http://research.africanstorybook.org/wordpress/

Wickens, C. M., \& Sandlin, J. A. (2007). Literacy for what? Literacy for whom? The politics of literacy education and neocolonialism in UNESCO and World Bank sponsored literacy programs. Adult Education Quarterly, 57(4), 275-292.

Winslow, S. M. (2015). Ethiopian manuscript culture: Practices and contexts (Unpublished doctoral dissertation.) University of Toronto, Canada 